\title{
Neuropathological and neurochemical aspects of generalized glycogen storage disease
}

\author{
L. CROME 1 , J. N. CUMINGS, AND S. DUCKETT \\ From the Queen Mary's Hospital for Children, Carshalton, Surrey, and \\ the National Hospital, Queen Square, London
}

Some 30 cases of generalized glycogenosis have been reported and many of the accounts contain brief references to the presence of glycogen in some part of the central nervous system. Very few appear to have been studied fully by neuropathological methods and no neurochemical findings have been hitherto reported. Advantage was therefore taken of an opportunity to study and record the following two further cases.

$$
\text { CASE } 1 \text { (C.G. 110/61) }
$$

There is no history of metabolic or neurological disease in the patient's family. A younger male sibling has been examined for glycogen storage disease and found to be healthy. The patient was delivered by the face a month before term, weighing $2 \mathrm{~kg}$. No abnormality was noticed during her early infancy. At $2 \frac{1}{2}$ months she was admitted to hospital for excision of a cutaneous haemangioma of the neck. She collapsed under anaesthesia but recovered after resuscitation. A radiograph taken at this time showed a grossly enlarged heart. The apex beat, 124 per minute, was located in the fourth intercostal space of the mid-axillary line. There were no murmurs or thrills. Her limb and back muscles were weak and lacked tone. She also appeared to be mentally retarded. Serum electrolytes were within normal limits, blood urea $43 \mathrm{mg}$., calcium $10 \mathrm{mg}$., and serum phosphate $4.3 \mathrm{mg}$. per $100 \mathrm{ml}$. The $\mathrm{Hb}$ was $12.4 \mathrm{~g} . / 100 \mathrm{ml}$. and the W.B.C.s $6,800 \mathrm{per}$ c.mm. No abnormal constituents were detected in the urine. The E.E.G. record is shown in Figure 1.

At 8 months she showed signs of respiratory infection and heart failure and died in spite of treatment with penicillin and digitalis.

\section{PATHOLOGICAL FINDINGS IN CASE 1}

The body was normal in size $(65 \mathrm{~cm}$.) and the head circumference measured $42 \mathrm{~cm}$., the average for 9 months being $44.7 \mathrm{~cm}$. with S.D. $\pm 1 \cdot 2$. A small cutaneous haemangioma, $1 \mathrm{~cm}$. in diameter, was situated in the left supraclavicular region. The heart was considerably enlarged $(160$ g.). The superior vena cava was normal and had a well-

'Part of the histological work was done with the aid of a grant by the National Society for Mentally Handicapped Children. developed Eustachian valve. The coronary sinus was normal and the Thebesian valve well developed; the foramen ovale was valvular with an opening measuring $3 \mathrm{~mm}$. The tricuspid valve measured $4 \mathrm{~cm}$., and the cusps and chordae tendineae were normal. The wall of the right ventricle was thickened up to $1 \mathrm{~cm}$. The pulmonary valve measured $2.5 \mathrm{~cm}$. The pulmonary trunk and branches were normal. The ductus arteriosus was closed. The left atrium showed uniform endocardial thickening. The mitral No valve measured $4 \mathrm{~cm}$. The wall of the left ventricle or was thickened up to $2 \mathrm{~cm}$., and there was a generalized is moderate endocardial thickening throughout the $\mathrm{N}$ chamber, especially marked near the apex. The 은 aortic valve measured $2.7 \mathrm{~cm}$. The coronary arter $\vec{P}$ and aorta were normal. The lungs (L. 39 g.; R. 70 go showed bilateral basal pulmonary collapse ang 0 purulent bronchiolitis. No macroscopic abnormali was seen in any of the other organs, although the liver was slightly enlarged $(300 \mathrm{~g}$.$) , the average$ weight for the age being $254 \mathrm{~g}$.

The brain weighed $638 \mathrm{~g}$. (average normal for age $714 \mathrm{~g}$.) and presented no macroscopic abnormality.

\section{HISTOLOGICAL FINDINGS IN CASE 1}

All tissues were fixed initially in $10 \%$ formol saline. The following day some were transferred and thereafter stored in absolute alcohol. The amount of histologically demonstrable glycogen was the same in both types of material. After embedding in paraffin glycogen was identified by staining with P.A.S. and with Best's carmine with and without prior treatment with diastase, sections being then counterstained with haematoxylin. There was no perceptible difference in the quantity of glycogen shown by either Best's carmine or P.A.S., although the glycogen $ᄋ$ was mainly granular with the former and more $\rightarrow$ diffuse and homogeneous with the latter. Haematoxylin and eosin and haematoxylin and van Gieson were used as routine histological stains.

All detectable glycogen was intracellular. The $\tilde{O}$ presence of very small amounts of this substance $\omega$ 
Corey Co. 8 miths. 98 OMC. $30-1061$<smiles>CCCCCCCCCCCCCCCCCCCCCCCCCCCCCCCCCCCCCCCCCC</smiles>

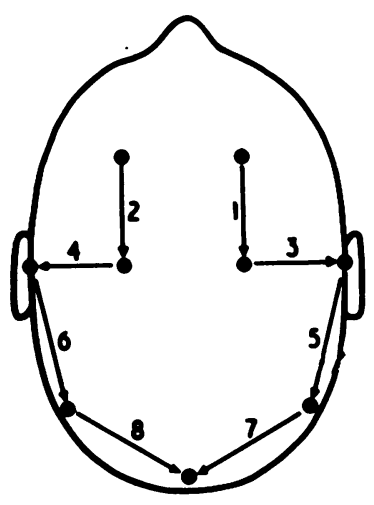<smiles>CCCCCCCCCCCCCCCCCCCCCCCCCCCCCCCCCCCCCCC</smiles>

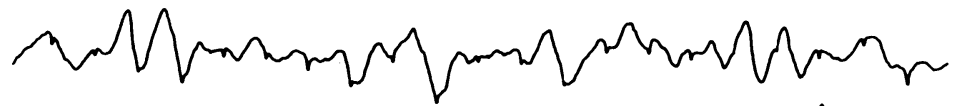

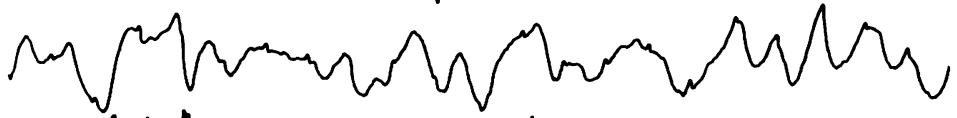

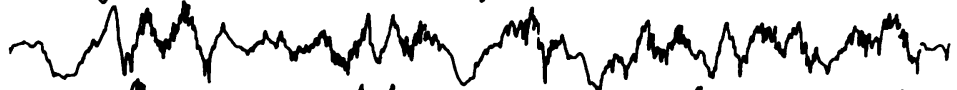

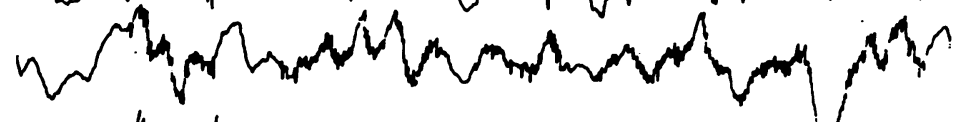

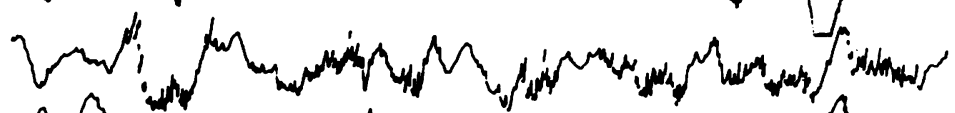

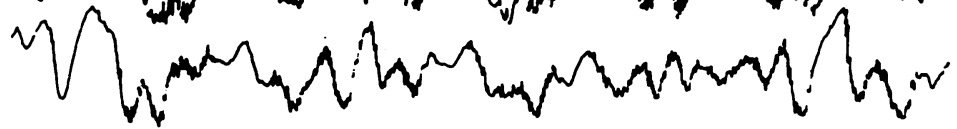
$\Omega_{\text {isec }} 100 \mu \mathrm{v}$
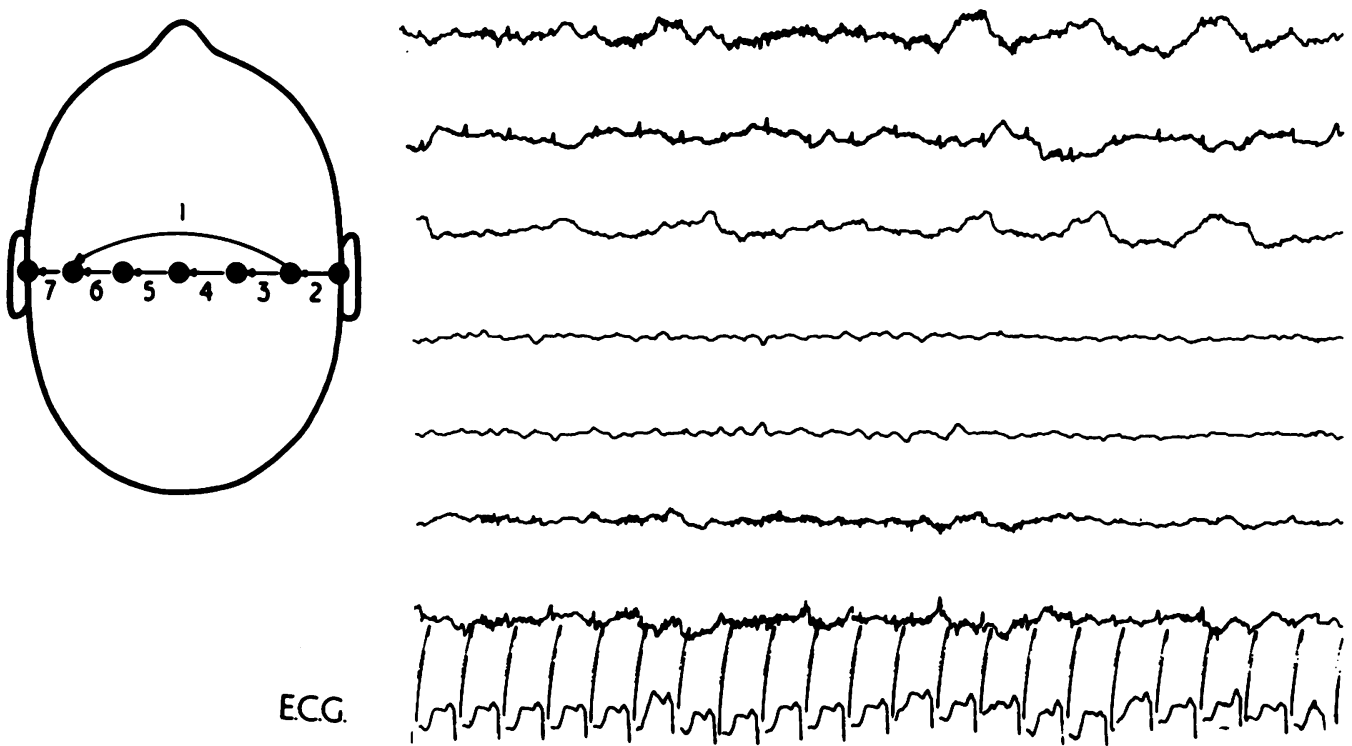

E.C.G.

FIG. 1. Electroencephalographic record of case 1. The upper portion shows an excess of irregular slow activity and the somewhat lower amplitude of the activity over the fronto-central regions. The bottom half of the illustration shows again the low amplitude activity in the paracentral regions and the gross electroencephalographic abnormality (report of Dr. G. Pampiglione). 
was associated with an otherwise normal appearance of the affected cells, but heavier storage was always accompanied by structural abnormality, which tended to be similar in all somatic tissues. The cells showed varying degrees of reticulation and vacuolation. With grosser involvement, the delicate septae of the intracellular reticulum tended to break down and form ragged 'empty' spaces within the cells. The nucleus remained central and the cytoplasm immediately around it was often spared. The cytoplasm around the cellular margin was also often intact and condensed. The polygonal outlines of contiguous cells in the epithelial organs, such as liver and kidney, were thereby accentuated. This, together with the cytoplasmic translucency, conferred a somewhat plant-tissue-like appearance on the affected areas. In appropriately stained sections there was seldom enough glycogen to account for the size and number of all the intracellular vacuoles and clefts.

The somatic tissues examined histologically comprised the liver, spleen, kidney, adrenals, cutaneous haemangioma, thymus, thyroid, parathyroid, skeletal muscle, pituitary, an artery, the heart, and a lymph gland.

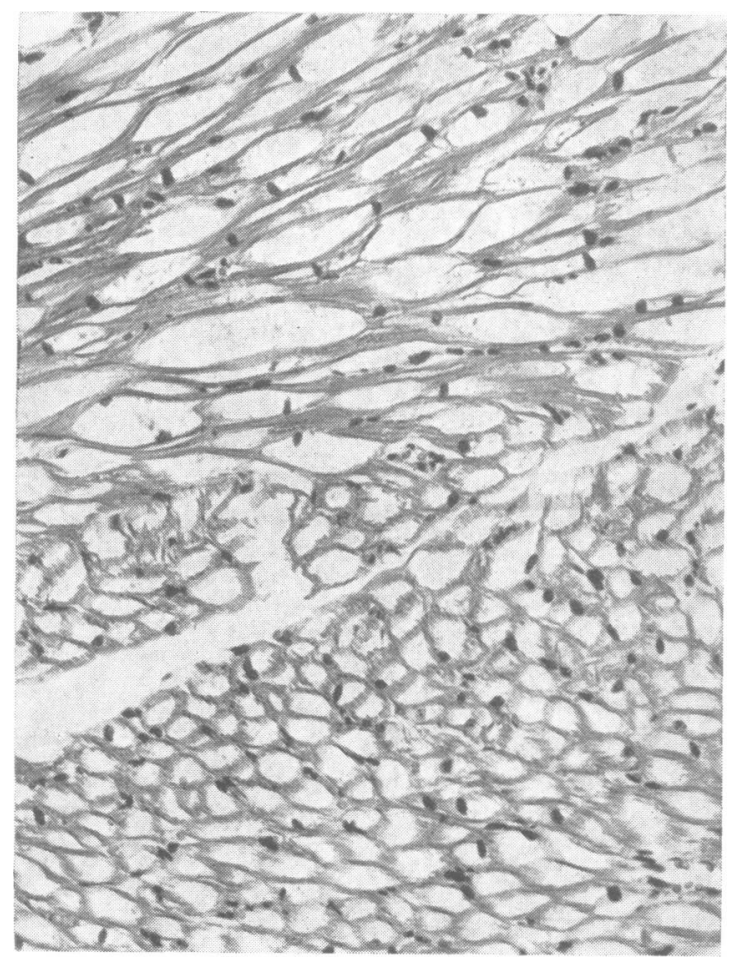

FIG. 2. Case 1. The heart. Haematoxylin and eosin $\times 200$.
The heart presented hypertrophy and vacuolation of most myocardial fibres, the tissue appearing lacelike on low magnification (Fig. 2). A large amount of glycogen was present in the capillary endothelial cells. There was slight endocardial fibrous thickening. Skeletal muscle fibres were also distended, vacuolated, and contained glycogen. The change was, however, by no means as widespread as in the heart. Grossly altered fibres alternated with many showing little morphological change, although some fine powdery glycogen was present in most fibres. Some of the vacuolated fibres contained in addition to glycogen rather coarse basophil, P.A.S.-positive, diastase-resistant particles. In the kidney glycogen granules were particularly numerous within the epithelial cells of the distal convoluted and the collecting tubules. The glomeruli contained little glycogen.

The liver showed gross deposition of glycogen throughout all parts of the lobule. Both parenchymatous and Kupffer cells were involved in the storage. The pituitary showed glycogen storage in many cells, particularly the eosinophil. The cortical cells of the adrenals contained fine powdery glycogen while storage within the medullary cells was lest marked. The Malpighian bodies in the spleen were्d 응 small and there was much phagocytic activity bq $\rightarrow$ cells in both the red and white pulp. Glycogen depost tion was slight, although a few small foci showe numerous cells containing a considerable amount $\mathbb{Q}$ 雨 glycogen. One lymph gland examined showed man phagocytic vacuolated cells in the sinuses, some of which contained a little glycogen. The thyroid epithelial cells were flattened and contained some glycogen. A little glycogen was also present in one of the parathyroid glands. A systemic artery showed some glycogen in the muscle fibres of the media. The lungs showed some collapse and early bronchopneumonia.

The histological appearances of the neural tissue were very similar in both cases and will be reported below after the second case record, followed by the neurochemical studies.

$$
\text { CASE } 2 \text { (C.G. B/96/61) }
$$

An older sibling died at 9 months from generalized glycogenosis. The patient was born after normal pregnancy and confinement, weighing $2.72 \mathrm{~kg}$. The neonatal period was normal, but he suffered later from recurrent bronchitis. Muscular weakness and lack of $D$ tone were noticed at 6 months. At 7 months he could sit, if supported, and play with toys, but he made no progress thereafter. At $10 \frac{1}{2}$ months his mother reported that he had become weaker and 'floppier'. He could no longer support ${ }^{1}$ Fuller clinical and pathological data relating to this case are to be published separately. 
himself in the sitting posture and did not crawl or kick his legs. Although slow over his feeds, he was generally alert and had commenced to say single words. When examined, his muscles were hypotonic. He lay in the 'frog position' with marked head lag on lifting. The cranial nerves seemed normal, tendon jerks being absent and plantar responses flexor. The optic discs were very pale. The liver was firm and extended about an inch below the costal margin. Radiographs showed generalized osteoporosis and enlargement of the heart. An electromyographic record was characteristic of myopathy. The diagnosis of glycogenosis was confirmed by muscle biopsy.

Soon after admission to hospital he developed pyrexia due to otitis media which responded to oral penicillin. However, five days later he became acutely dyspnoeic and unable to swallow. This was followed by diarrhoea for four days. Death followed rapid deterioration of his condition.

Necropsy (performed by Dr. N. E. France) showed generalized enlargement of the heart $(117 \mathrm{~g}$.), with increased thickness of all chamber walls, especially the left ventricle. The lungs showed oedema and collapse. The liver was considerably enlarged (557 g.). The blood vessels at the base of the brain were rather turgid. There was slight dilatation of the lateral ventricles, but no other macroscopic abnormality of the brain. Histologically there was generalized vacuolation of the myocardium, although glycogen could only be demonstrated with difficulty. Skeletal muscle changes included vacuolation due to accumulation of glycogen. Most of the liver cells were of normal size with foamy cytoplasm and excessive quantity of glycogen.

\section{HISTOLOGICAL FINDINGS IN THE CENTRAL NERVOUS SYSTEM IN CASES 1 AND 2}

After prolonged fixation in $10 \%$ formol saline blocks taken from the frontal, parietal, occipital and temporal lobes, the basal ganglia, the midbrain, pons, medulla, and cerebellum in both cases, as well as several levels of the spinal cord in case 1 , were embedded in celloidin and in paraffin and sections stained for glycogen. Celloidin preparations were also treated with haematoxylin and eosin, haematoxylin and van Gieson, P.T.A.H., cresyl violet, and by the Holzer method for fibrous glia and the Heidenhain method for myelin. Frozen sections were employed for the usual neuropathological silver impregnation methods and for fat staining with Scarlet R and Oil Red O.

The histological findings can perhaps be best presented under the following headings: glycogen storage, other neuronal changes, and associated changes.

GLYCOGEN STORAGE Glycogen storage was immediately apparent at all levels, while in the spinal cord and brain-stem almost all cells seemed affected, especially in case 1 .

With Best's carmine, glycogen appeared in the form of fine, discrete, red, dust-like particles (Fig. 3). The deposition was patently intracellular in the case of nerve cells, although a few granules could occasionally be seen outside but in the immediate vicinity of the perikaryon. The amount of glycogen deposited in neurones varied enormously from none to dense filling of the cytoplasm and proximal, irregularly dilated, dendritic and axis processes. Nuclei were as a rule free from glycogen, but a few nucleoli were glycogen positive. In general, and with many exceptions, cells most involved in glycogen storage were multipolar pyramidal cells, as in the motor nuclei of the cranial nerves and the anterior horns of the spinal cord. Less glycogen was present in the larger rounded neurones and, often, none in the smallest, such as the cerebellar granular cells. Within the same area neighbouring cells often contained vastly different amounts of glycogen. Since the cytoplasm of glial cells is not normally demonstrable by methods used for glycogen demonstration, the storage in them seemed at first glance extracellular. Closer examination showed, however, that the findings were more consistent with intracellular storage, the deposition within the invisible processes appearing somewhat like hoar frost.

A fair amount of glycogen, greater in case 2, was present in the delicate septae of the intrameningeal channels. The media of arteries, both in the subarachnoid space and within the substance of the brain, was heavily involved by glycogen storage.

Glycogen was very conspicuous in the cerebral molecular layer (Fig. 4) and the subpial portions of the brain-stem and spinal cord, where it affected most of the glial cells and processes. Microglia seemed as affected as astrocytes. The cytoplasm of capillary endothelial cells in all parts of the brain often contained glycogen granules.

In the cerebral cortex, glycogen storage was much more evident in case 1 than in case 2 , involving mostly the larger and best differentiated cells. The hippocampus seemed to contain more glycogen than other areas; it was present in the end-folium and fascia dentata but was not very evident in the pyramidal layer. The striate body and thalamus contained little glycogen but storage was quite marked in neurones of the globus pallidus and the nucleus of the ansa lenticularis. Much glycogen was also present in ependymal cells and in the choroid plexuses (Fig. 5).

In the brain-stem the heaviest storage was in the larger multipolar cells of the cranial nerve nucleiIII, IV, V, VI, VII, XII-and the nucleus ambiguus. Other formations, such as the cuneate and gracile nuclei, the nucleus of the eighth and tenth nerves, the nuclei pontis, reticular formation, substantia nigra, and red nuclei showed variable, but usually no more than moderate, glycogen deposition. Nerve 


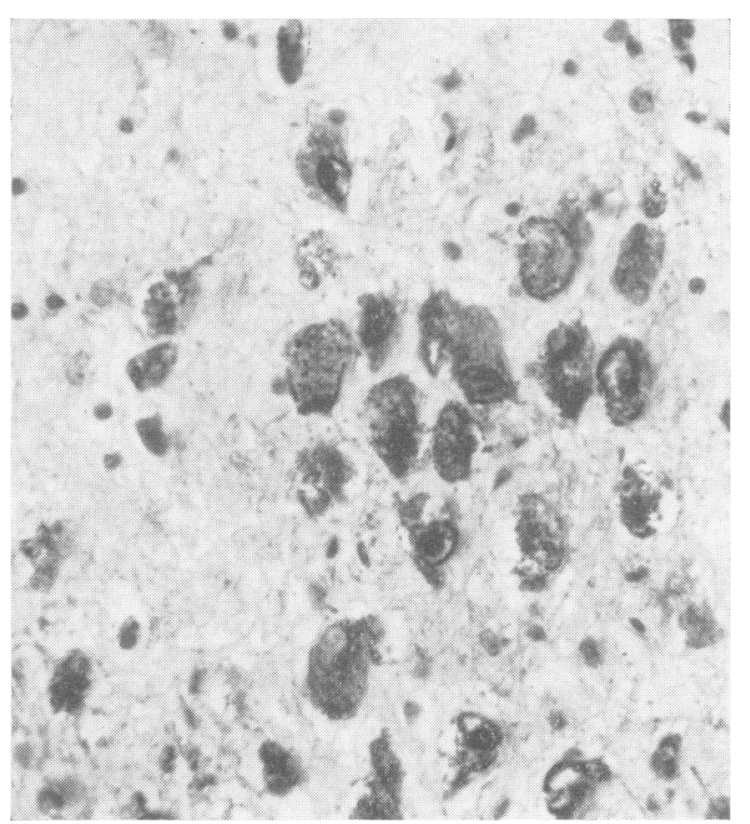

FIG. 3

FIG. 3. Case 1. Nerve cells in the eighth nerve nucleus stained with Best's carmine and haematoxylin $\times 375$.

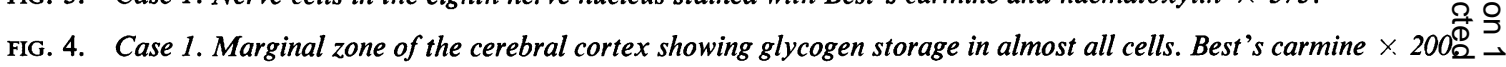

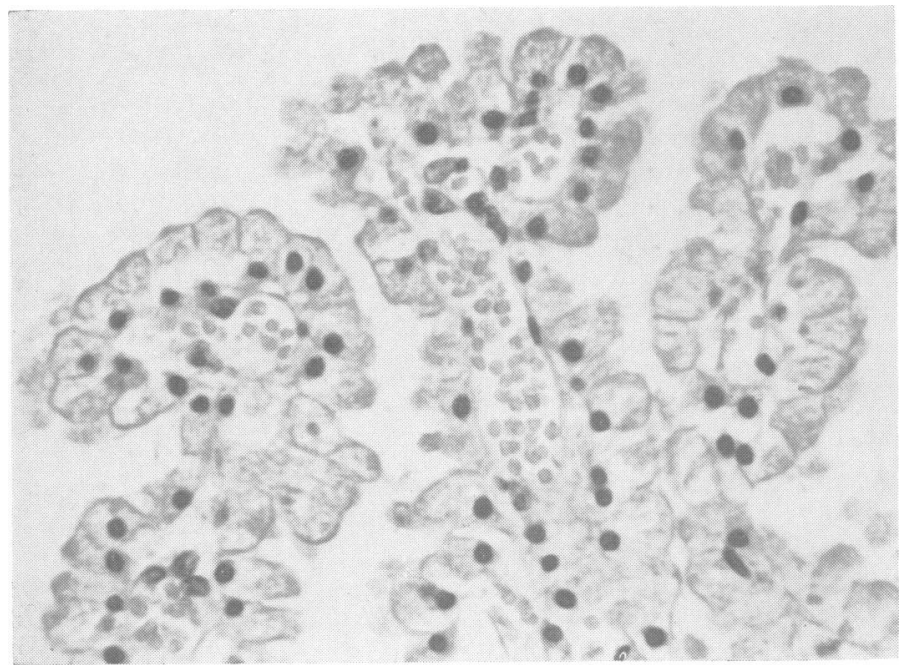

FIG. 5

FIG. 5. Case 1. Cytoplasmic porosity and reticulation of cells of the choroid plexus. Haematoxylin and eosin $\times 375$.

FIG. 6. Case 1. Cytoplasmic reticulation of neurones in a dorsal root ganglion. Haematoxylin and eosin $\times 500$.

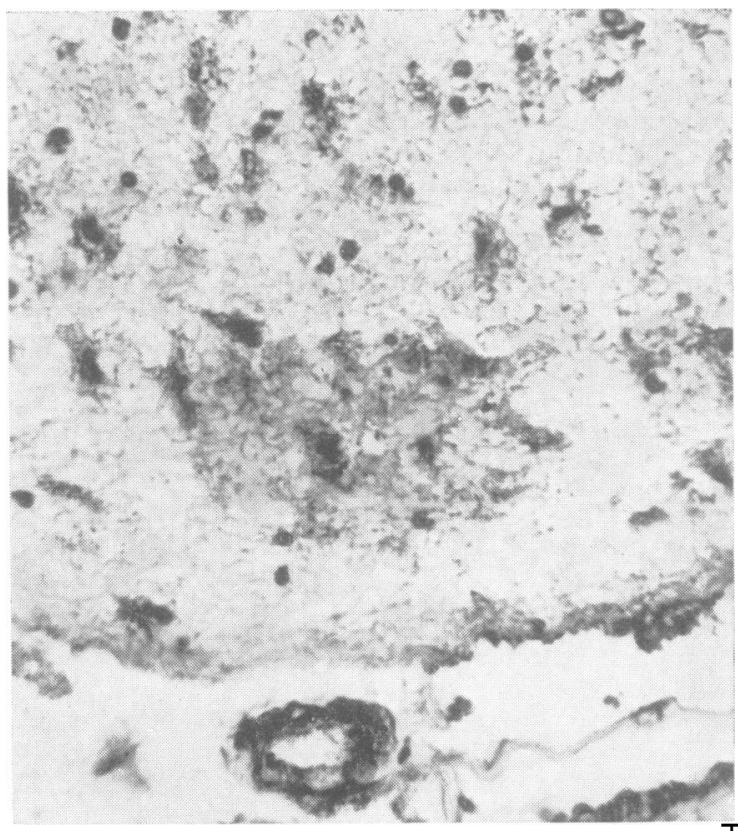

FIG. 4

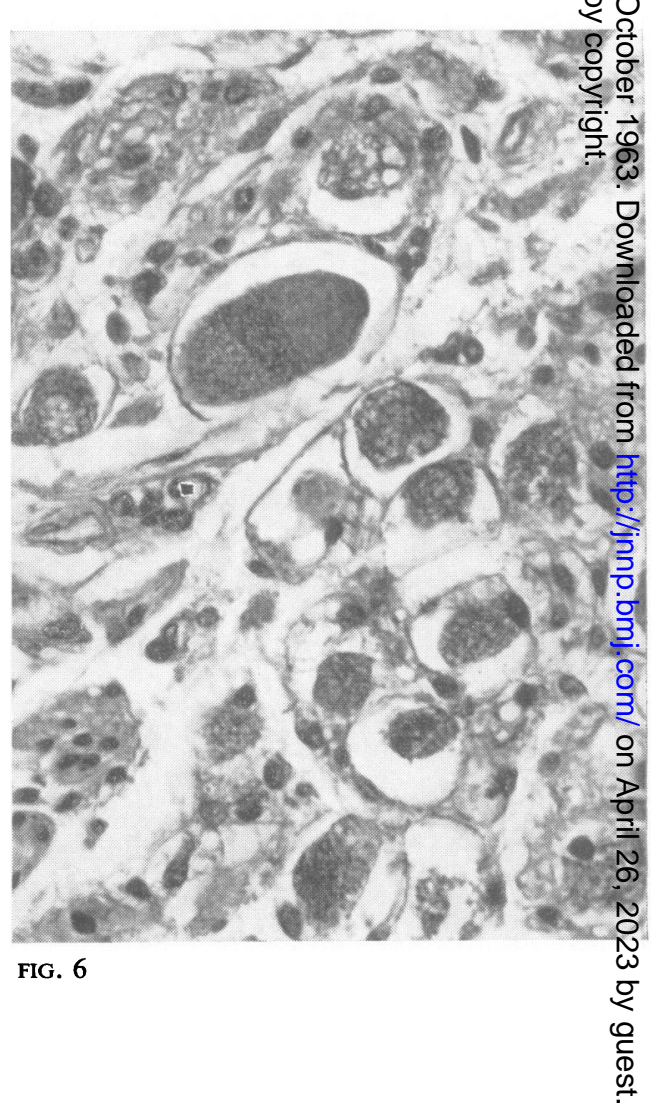


cells of the inferior olives contained little demonstrable glycogen in case 2 but much of it was present in the hypertrophied and hyperplastic astrocytes situated in that formation. The inferior olives of case 1 were quite heavily affected. All but the smallest neurones of the spinal cord were involved in case 1 . (The spinal cord of case 2 was not available for study.)

In all parts of the white matter astrocytes and oligodendrocytes showed considerable glycogen deposition. In the cerebral centrum semiovale glycogen was also seen in the ectopic nerve cells which are still normal in infants of this age.

Compared with other parts of the brain the cerebellum was relatively free from glycogen, that of case 1 containing a little more than the other. The Purkinje cells contained a little demonstrable glycogen in case 1 but not in case 2 ; deposition was present in the Golgi type II cells of the granular layer and astrocytes in the white matter. Cells of the dentate nuclei contained little demonstrable glycogen in case 2 but were quite heavily affected in case 1 .

One dorsal root ganglion and several peripheral nerves of case 1 were examined and showed plentiful glycogen in the nerve cells of the dorsal root ganglion (Fig. 6) and Schwann cells of the peripheral nerve.

OTHER NEURONAL CHANGES In addition to the glycogen storage, many neurones presented other striking changes demonstrable in sections irrespective of the staining. The mildest of the lesions were disappearance or fragmentation of the Nissl substance in a part of the cytoplasm. Fine cytoplasmic strands enmeshed minute vacuoles in the affected areas, in a foam-like manner (Fig. 7 and Fig. 8), and the cytoplasm appeared like frosted glass in some of the thicker celloidin-embedded sections. The cytoplasm with its Nissl bodies tended to be spared around the nuclei. As lesions enlarged, the delicate reticulum seemed to break down, leaving in its place irregular clefts and spaces (Fig. 9). A peripheral cytoplasmic condensation was occasionally present in such severely affected cells. In contrast to other storage diseases of neural tissue, nuclei were seldom displaced into the apical dendrites or towards the periphery of the cell, although some of the most degenerate cells were rounded and swollen.

In general, there was satisfactory correspondence between the above cellular vacuolation and the amount of glycogen deposition. The distribution was similar, the large multipolar cells being most affected by both sets of processes. Correspondence was also fair within single neurones, cells showing most glycogen deposition but also being more ragged. Nevertheless, a few of the severely affected cells showed little or no glycogen, perhaps because of diffusion or other processing artefacts, while many neurons, especially the smaller or rounder ones, showed only doubtful cytoplasmic reticulation despite more substantial glycogen deposition.

Many cells showed other marked structural change, unrelated to glycogen deposition. Thus, the cerebral neurones of both cases showed marked perinuclear vacuolation, such as is usually associated with oedema, with only minimal glycogen deposition. Similarly many nerve cells showed unevenness of staining, central chromatolysis, homogenizing change, and conversion to 'ghost' form. It is evident that there had been a variable but appreciable amount of diffuse neuronal loss. There was also focal loss of Purkinje cells with proliferation of Bergmann glia, more marked in case 2 .

ASSOCIATED CHANGES The most conspicuous of the other changes was fine fibrous gliosis of the white matter (Fig. 10). This was present in all parts of the brain, being particularly evident in the cerebral subpial layer and in the cerebellum. This gliosis tended to be accentuated around blood vessels and was associated with astrocytic hypertrophy and hyperplasia. In the brain-stem it also affected the grey matter.

The degree of myelination and its topological maturity were in keeping with the age of the patients, although the myelin stained, perhaps, paler than normally. There was no evidence of demyelination, and a little sudanophil material was present only in a few compound granular corpuscles around vessels and in some capillary endothelial cells.

The hippocampus of case 2 showed a curved zone of spongy degeneration between the pyramidal layer and fascia dentata.

\section{BIOCHEMICAL STUDIES IN CASES 1 AND 2}

Portions of brain and of various organs were examined for glycogen, lipid, and water content. The latter was obtained by drying representative samples to constant weight at room temperature in vacuo. Cerebral lipids were extracted by the procedure of Folch, Lees, and Sloane Stanley (1957) using a 2:1 chloroform-methanol solvent $(\mathrm{v} / \mathrm{v})$. Estimations on the extracts were made of total phospholipid, total and free cholesterol, and of cerebroside by methods used previously (Cumings, 1953). Total hexosamine was measured (Cumings, 1957) while the method for neuraminic acid employed was the colorimetric technique of Svennerholm (1957) following extractive procedures of Long and Staples (1959). Glycogen was estimated by the method of Hildes, Sherlock, and Walshe (1949). 


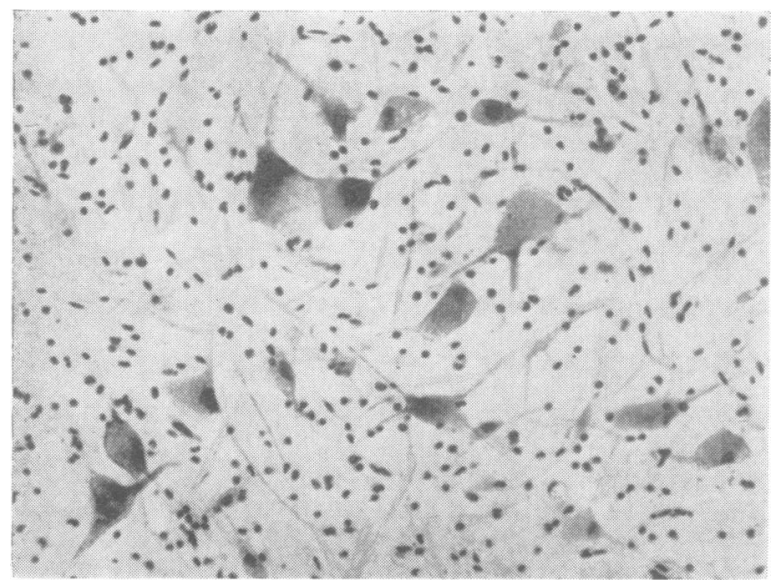

FIG. 7. Case 1. Foam-like appearance of cytoplasm in the anterior horn cells. Haematoxylin and van Gieson $\times 150$.

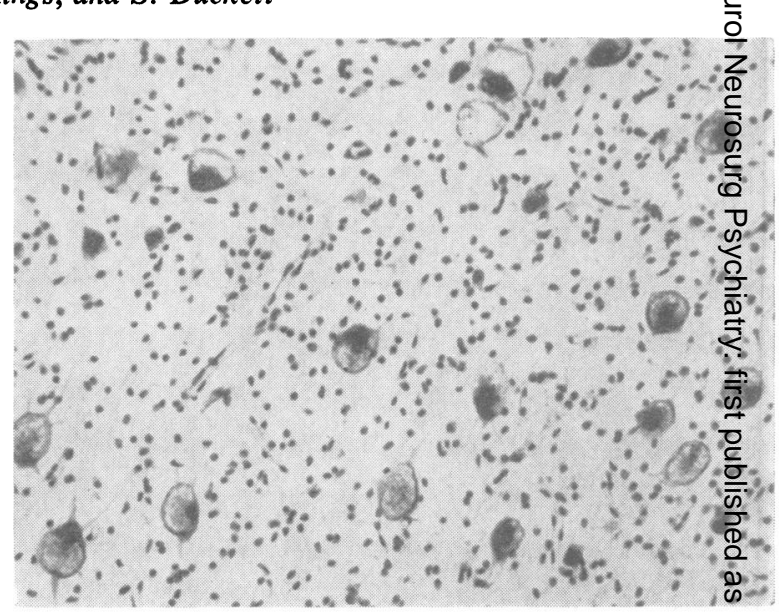

FIG. 8. Case 1. Cytoplasmic vacuolation of neurones. Haematoxylin and van Gieson $\times 150$.

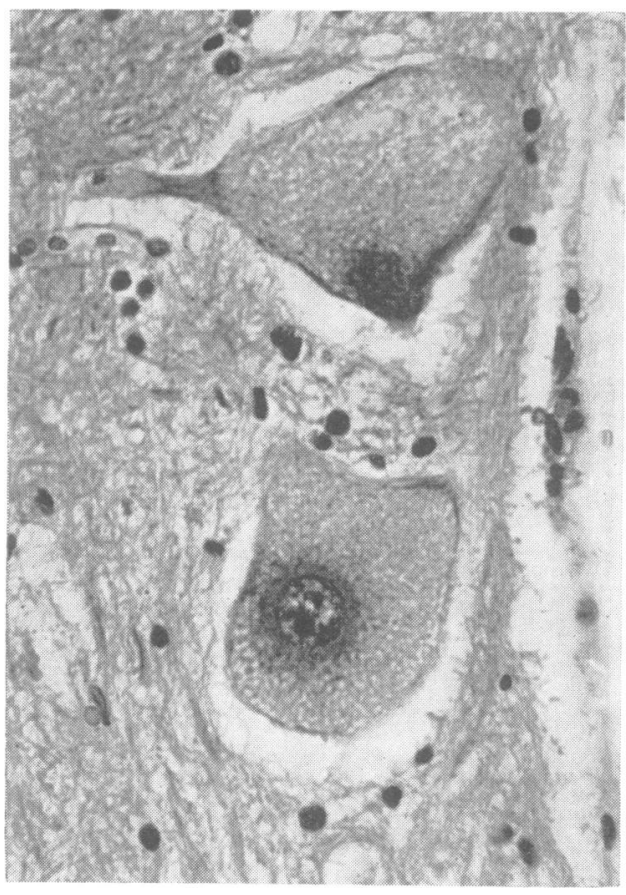

FIG. 9. Case 1. Foam-like appearance of cytoplasm of anterior horn cells. Haematoxylin and eosin $\times 500$.

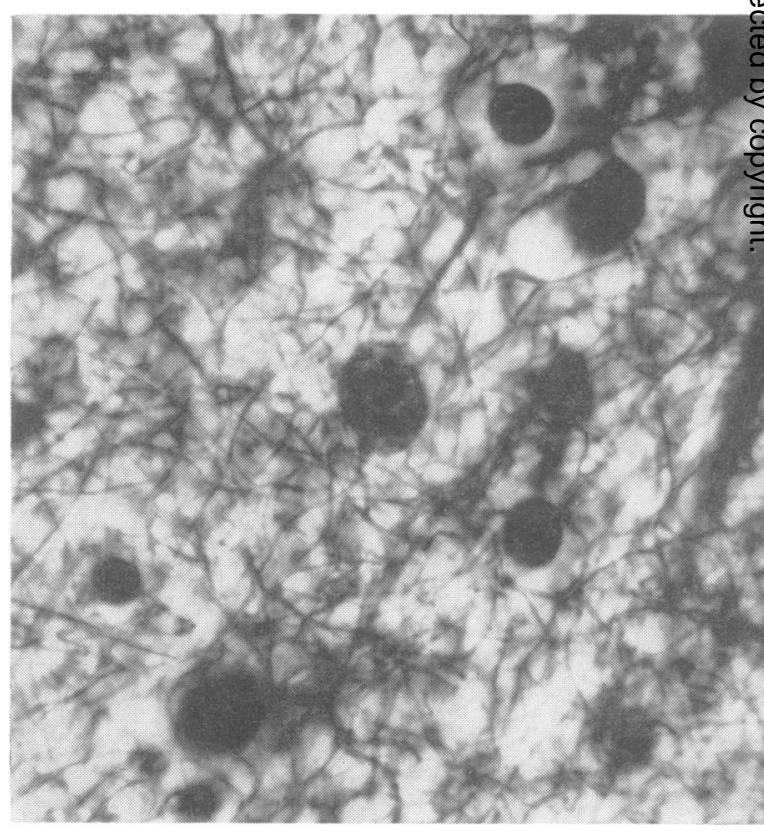

FIG. 10. Case 1. Fine fibrillary gliosis of the white matter. Holzer $\times 1,000$. 
TABLE I

\begin{tabular}{|c|c|c|c|c|c|c|c|}
\hline & & & LYCOGEN CONT & NT IN TISSUES & & & \\
\hline & Cerebral White & Cerebral Cortex & Cerebellar White & Cerebellar Cortex & Heart & Liver & Spleen \\
\hline $\begin{array}{l}\text { Case } 1 \\
\text { Case } 2\end{array}$ & $\begin{array}{l}3 \cdot 67 \\
3 \cdot 56\end{array}$ & $\begin{array}{l}3.0 \\
0.65\end{array}$ & $\begin{array}{l}3 \cdot 2 \\
2 \cdot 22\end{array}$ & $\begin{array}{l}2 \cdot 3 \\
0.44\end{array}$ & $28 \cdot 2$ & $24 \cdot 0$ & $7 \cdot 6$ \\
\hline
\end{tabular}

Results in $\mathrm{g} . / 100 \mathrm{~g}$. dry tissue.

TABLE II

\begin{tabular}{|c|c|c|c|c|c|c|c|}
\hline & & & CEREBRAL & IDS & & & \\
\hline & $\begin{array}{l}\text { Total } \\
\text { Phospholipid }\end{array}$ & $\begin{array}{l}\text { Total } \\
\text { Cholesterol }\end{array}$ & $\begin{array}{l}\text { Esterified } \\
\text { Cholesterol }\end{array}$ & Cerebroside & $\begin{array}{l}\text { Total } \\
\text { Hexosamine }\end{array}$ & $\begin{array}{l}\text { Neuraminic } \\
\text { Acid }\end{array}$ & $\begin{array}{l}\text { Water } \\
(\%)\end{array}$ \\
\hline Case 1 & & & & & & & \\
\hline Cerebral white & $17 \cdot 0$ & $8 \cdot 2$ & 0 & $6 \cdot 8$ & 0.7 & & $72 \cdot 2$ \\
\hline Cerebral cortex & $19 \cdot 4$ & $7 \cdot \overline{7}$ & $0 \cdot 3$ & $5 \cdot 8$ & 0.9 & 0.4 & $80 \cdot 7$ \\
\hline Cerebellum & $11 \cdot 0$ & $2 \cdot 2$ & 0.2 & $2 \cdot 6$ & 0.9 & & $71 \cdot 4$ \\
\hline Heart & $0 \cdot 3$ & 0.45 & 0 & 0.75 & 0.8 & & $73 \cdot 5$ \\
\hline Liver & 0.8 & 0.40 & 0 & 0.6 & 0.9 & & 62.9 \\
\hline Spleen & $2 \cdot 5$ & 0.8 & 0 & $1 \cdot 1$ & 0.8 & & $67 \cdot 7$ \\
\hline Case 2 & & & & & & & \\
\hline Cerebral white & $17 \cdot 3$ & $9 \cdot 7$ & 0 & $8 \cdot 75$ & 0.35 & & $75 \cdot 9$ \\
\hline Cerebral cortex & 11.9 & $6 \cdot 0$ & $\mathbf{0}$ & $2 \cdot 1$ & 0.6 & $0 \cdot 3$ & $83 \cdot 2$ \\
\hline Cerebellar white & $14 \cdot 4$ & $9 \cdot 3$ & 0 & 6.6 & $0 \cdot 3$ & & $75 \cdot 7$ \\
\hline Cerebellar cortex & $11 \cdot 2$ & $5 \cdot 9$ & 0.3 & $1 \cdot 5$ & 0.7 & & $82 \cdot 1$ \\
\hline
\end{tabular}

Results in g. $/ 100$ g. dry tissue.

The results of the various estimations in the two cases are given in Tables I and II.

It is seen from Table I that there is a considerable excess of glycogen in all organs and that while well marked in the brain it is especially marked in the heart in case 1 . Levels in the cerebral cortex in case 2 are not greatly increased.

The cerebral lipids show a well-marked deficiency, especially in total phospholipid, cholesterol, and cerebroside. However, no active demyelination is present as indicated by an absence of cholesterol esters. Total hexosamine and ganglioside are normal for the ages of the two children. The organs show practically no abnormality in lipid composition.

\section{DISCUSSION}

Many of the published neuropathological accounts are confined to the barest mention of a few sites of glycogen deposition in the brain (Hertz and Jeckeln, 1936; Esser and Scheidegger, 1937; Günther, 1939; Mason and Andersen, 1941; Schneider, 1946; Wachstein, 1947; Clement and Godman, 1950; Childs, Crose, and Henderson, 1952; Gitzelmann, 1957; Jean and Miller, 1960; Stoeckle, Goldman, and Webb, 1961; Muller, Bellet, and Ertrugrul, 1961 ; and Caddell and Whittemore, 1962). The fullest reports are perhaps by Kimmelstiel (1933) and Selberg (1955), the latter containing a neuropathological description of the case by Jacob. In spite of the considerable diversity of presentation and inter- pretation in the above reports, it is clear that the findings have been remarkably similar and that they resemble closely those in the present cases. This is, perhaps, not surprising in view of the similarity in the ages of the patients, most of whom died towards the end of their first year. Features which received most attention were glycogen storage, most marked in larger neurones and in glial cells, and the cytoplasmic porosity of the neurones. All but one of the reports have noted the absence of glycogen in the cerebellar Purkinje cells, the exception being that of Caddell and Whittemore, whose case also showed a higher average content of brain glycogen $(3.6 \%)$. The Purkinje cells of the present case 1 also contained some glycogen. Selberg has noted the absence of glycogen deposition in the nerve cells of Clarke's column. This nucleus was, however, affected in the first of the present cases.

Only a few of the authors have recorded the weight of the brains and this was within or a little below normal limits. No other macroscopic abnormality and been described, although Selberg (1955) and Muller, Bellet, and Ertrugrul (1961) had observed some induration of the brains of their cases. In view of the widespread fibrous gliosis in the present cases and a similar change in the only previously recorded instance where this was looked for (Selberg), some induration might have been also expected in other cases, were it not that most of these were apparently examined after fixation.

Although it is clear that the cytoplasmic porosity 
and vacuolation is directly related to glycogen deposition in most neurones, no precise correspondence between the two changes can be expected in fixed post-mortem material because of variable rate of fixation, glycogen diffusion, and other processing effects. It is, indeed, possible to find no glycogen whatever in some undoubted cases of neuronal glycogenosis. This was so in the case described by Günther. Thus, failure to detect histologically demonstrable glycogen in the brains of cases of glycogenosis cannot be regarded as absolute evidence of its absence (Gitzelmann, 1957), and this consideration must also apply to suggested classifications based on the presence or absence of glycogen in neural tissue.

In addition to intracellular storage, some glycogen may seem to be extracellular (Kimmelstiel, 1933). That such appearances can be equivocal is evident from the study of the present cases. It seems that when granules of glycogen are found outside cells this is the result of either shrinkage artefacts, displacement in processing, or, possibly, liberation of the substance from a few perished cells.

The neural morphological changes in glycogenosis appear to be both specific and non-specific. The specific is excessive deposition of glycogen, while the non-specific are fibrous gliosis and, possibly, slight micrencephaly. This is in keeping with the neurochemical findings which also show an excess of demonstrable glycogen on the one hand, and a deficiency of cerebral lipids without active demyelination, on the other.

\section{SUMMARY}

The central nervous system in two infants dying with generalized glycogenosis at 8 and 11 months of age was studied by neuropathological and neuro- $\underset{\mathbb{D}}{Z}$ chemical methods. Widespread neuronal and glial glycogen storage was present in both cases, and many neurones showed also progressive cytoplasmic $\underset{0}{\stackrel{C}{a}}$ vacuolation. In addition, there was generalized fibrous gliosis of the white matter and the grey matter of the brain-stem. An excess of glycogen was present in all organs of both cases. The cerebral

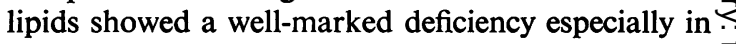
total phospholipid, cholesterol, and cerebroside. Cholesterol esters were normal.

We are deeply indebted to Dr. H. M. T. Coles for permission to record the clinical findings of case 1 and to Drs. R. J. K. Brown, N. E. France, and R. F. Mahler $\stackrel{D}{\Omega}$ for some of the data in case 2.

\section{REFERENCES}

Caddell, J. L., and Whittemore, R. (1962). Pediatrics, 29, 743. Childs, A. W., Crose, R. F., and Henderson, P. H. (1952). Ibid., 10, 208.

Clement, D. H., and Godman, G. C. (1950). J. Paediat., 36, 11.

Cumings, J. N. (1953). Brain, 76, 551.

(1957). In Cerebral Lipidoses: A Symposium, edited by J. N. N

Cumings, p. 112. Blackwell, Oxford.
Esser, M., and Scheidegger, S. (1937). Schweiz. med. Wschr., 18, 970

Folch, J., Lees, M., and Sloane Stanley, G. H. (1957). J. biol. Chem N 226, 497.

Gitzelmann, R. (1957). Helv. paediat. Acta., 12, 425.

Günther, R. (1939). Virchows Arch. path. Anat., 304, 87.

Hertz, W., and Jeckeln, E. (1936). Z. Kinderheilk., 58, 247.

Hildes, J. A., Sherlock, S., and Walshe, V. (1949). Clin. Sci., 7, 28

Jean. C.. and Miller, G. (1960). Laval méd., 29, 447.

Kimmelstiel. P. (1933). Beitr. path. Anat., 91, 1.

Long, C., and Staples, D. A. (1959). Biochem. J., 73, 385.

Mason, H. H., and Andersen, D. H. (1941). Amer. J. Dis. Child., 61 795 .

Muller, O. F., Bellet, S. , and Ertrugrul, A. (1961). Circulation, 23, 26ج्干t

Schneider, J. (1946). Helv. paediat. Acta., 1, 368.

Selberg, W. (1955). Z. Kinderheilk., 72, 306.

Stoeckle, H., Goldman, A. S., and Webb, J. A. (1961). Amer. J. Cardiol., 8, 675 .

Svennerholm, L. (1957). In Cerebral Lipidoses: A Symposium, edited by J. N. Cumings, p. 139. Blackwell, Oxford.

Wachstein, M. (1947). Amer. J. med. Sci., 214, 401. 